Peer-Reviewed Article

ISSN: 2162-3104 Print/ ISSN: 2166-3750 Online

Volume 6, Issue 2 (2016), pp. 527-541

(C) Journal of International Students

http://jistudents.org/

\title{
How Do We Get People to Interact? International Students and the American Experience
}

\author{
Danielle Geary \\ Georgia Institute of Technology (USA)
}

\begin{abstract}
American colleges and universities consider diversity a way to foster personal growth and a healthy society, challenge stereotypes, encourage critical thinking, and help students communicate and feel comfortable with people they may perceive to be different. Quality interaction that has the potential to grow into authentic relationships between Americans and international students may be the bridge to affecting these outcomes, but how do we get people to interact? In this article, based on research as well as her own experience as an international student, the author explores some of the challenges international students face and suggests ideas for sparking interaction between international students and Americans.
\end{abstract}

Keywords: international students, cultural exchange, diversity, authentic friendships, student interaction

In 2012, over 900,000 international students studied in the US, yet an estimated 80 percent of them never set foot in an American home while visiting the United States (Bridges International, 2012). This statistic, by an organization that networks to provide assistance to international students, makes quite an impression on the challenges international students face in assimilating to the American culture. International students have a number of needs that educators must 
meet in order to provide the best study abroad experience possible, but it is a complicated undertaking for colleges and universities, as well as the international students themselves. Clearly, there is often a disconnect between international students and an authentic American learning experience, which might include things like attending birthday parties, religious celebrations, pot-luck dinners and sporting events, being exposed to regional foods and cultural pastimes, and spending time with an American family.

Higher Education (HE) institutions share a common belief that diversity in their student bodies is important for them to achieve their goal of providing a quality education (Simmons, 2011). Administrations also consider diversity a way to foster personal growth and a healthy society, challenge stereotypes, encourage critical thinking, and help students communicate and feel comfortable with people they may perceive to be different (Hurtado, 2007). According to the Institute for International Education (2014), the number of foreign students studying in the United States has grown enormously over the years - from roughly 48,000 in 1960 to over 886,000 by 2014 . International students enrich the educational community and learning environment of the institution, contribute billions of dollars to the U.S. economy, and help build U.S. Ph.D. programs due to the high proportion of international students that comprise graduate education departments across the country (Orchowski, 2008). Clearly, it is imperative for colleges and universities across the nation to meet the needs of their international students in this increasingly global society.

\section{STATEMENT OF THE PROBLEM}

With such diversity come challenges, and even more so in regard to students from other countries who often arrive in the United States with communication difficulties and little to no knowledge of societal norms and culture. The international student population experiences an array of problems, some of which include language barriers, difficulty making American friends, academic challenges, and difficulties in psychological and sociological adjustment to their new environment (Telbis, Helgeson, \& Kingsbury, 2014). According to Rose-Redwood (2010), even though colleges and universities have 
focused on enrolling more international students during the decades since WWII, they are struggling considerably in "stimulating diverse social interactions between the international and American student body" (p. 389). Hence, assimilating to a new culture is imperative to international students' success and contentment during their stay in the United States. American HE institutions need to find ways to meet international students' needs to ensure that, in the coming years, they continue to choose the U.S. as their overseas study destination.

\section{LITERATURE REVIEW}

\section{Cultural and Social Adjustments of International Students}

Just as American students face challenges when they begin college in their own country, international students must overcome a variety of obstacles in order to be successful and content in a foreign country. They must adapt not only to a new university, but to a new academic system, a new culture, and more often than not, a new language as well. Thus, it makes sense that the cultural and social adjustments for international students can be overwhelming. Many of them feel isolated from social contact with Americans and need help adapting to the culture via social relationships (Korobova \& Starobin, 2015). Indeed, satisfactory interpersonal relationships are most important during the transition from adolescence to adulthood (Patron, 2014), so this task is especially important for this age group. They generally report feeling lonely and homesick during their time in America though to different degrees depending on a variety of factors and individual experiences. It should be noted that there may be a lack of awareness on the part of Americans in that they may not realize how important it is to reach out to international students and include them in their activities due to Americans' unique individualistic nature that can be puzzling to people from other cultures (Yan and David, 2011). Repeatedly, social support in many forms - from friends, classmates, church groups, and counseling - has proven to be the premier resource in international students successfully coping with cross-cultural challenges (Yan \& David, 2011). However, "cultural loneliness," a form of loneliness that is cultivated from the loss of a native cultural and language background, 
often times is not eased by social support in the target country, which may be why international students often lean on and form friendships primarily with their fellow nationals for consolation (Patron, 2014).

In addition to the factors already mentioned, students' age at the time of arrival in the U.S. also impacts the ease or difficulty of acculturation (Kwon, 2011). Undergraduates seem to learn English, make friends and adjust to American customs faster and more easily than do graduate students. Graduate students struggle more with cross-cultural challenges, financial difficulties, and visa and immigration worries. They sometimes cannot understand or accept American values and behaviors and do not particularly want to communicate with Americans because they consider them to be too different. As one graduate student reflected, "I do not have the same opinion as these people. I do not want to communicate with them. They are very different from me" (Yan \& David, 2011, p. 529).

\section{Language Barriers and International Students}

Research has shown that perhaps the most serious problem international students face in the United States were related to limited English language proficiency, which affects their ability to communicate, comprehend, and interact on both an academic and social level in their new environment (Telbis, Helgeson, \& Kingsbury, 2014). International students cite difficulty understanding lectures and participating in discussions as well as personal conversations in social situations (Kwon, 2011; Jang, 2010). Such barriers often lead to feelings of loneliness and isolation because language proficiency is crucial to not just interaction with Americans, but also for quality social interaction (Jang, 2010). Furthermore, students' own perceptions of their English language skills had an impact on successfully integrating into American society; "the better international students perceived their English proficiency, the better they became accustomed to English environmental classes without experiencing feelings of isolation or intimidation" (Kwon, 2011, p. 1024).

\section{Day-to-Day Life and International Students}

Day-to-day affairs, such as living arrangements, paying bills, and orientation problems, are another important element of 
international students' adjustment to the United States. For instance, research implied that living with Americans is the best way for international students to learn about daily life - through leisure time and naturally getting to know Americans and how they do things (Jang, 2010; Yan \& David, 2011). Clearly, new food, housing, a different climate, and learning how to make purchases and payments can be especially challenging for international students since, apart from attending class, they must also learn how to pay their tuition and fees, write out checks, decipher new business terminology, and find general information about the campus and surrounding area (writer's personal experience). Other kinds of orientation challenges included United States' law enforcement customs and the concept of being an international student and relating to Americans (Jang, 2010). As asserted by Telbis, Helgeson, and Kingsbury (2014), "students experience stress and anxiety when faced with community acceptance/comfort, language mastery, academic preparation, and financial solvency issues" (para. 3).

\section{Current Practices in the field of Higher Education}

To assist international students with the transition to a very different life in the United States, HE international offices and student services divisions are designing programs to help foreigners overcome an array of challenges, especially during their first year. Arizona Western College, for example, has been an innovator in reaching international students by implementing unique ideas. Arizona Western is a community college that has connected the international students program and the college's Honors Program as a way to build relationships between foreigners and Americans. They offer a one-credit orientation course to all new international students, a cross-cultural studies course open to all members on campus, and a Global Leadership Retreat (Bowman, 2011).

The one-hour orientation course provides information that is helpful to international students as they settle into their new surroundings, and then evolves into an ongoing weekly class meeting to discuss both academic and cultural concerns that inevitably surface throughout the semester. The three-credit culture course is comprised of both Americans and international students and involves daily group work to help "overcome the normal difficulty international students 
have in communicating and connecting with American students and vice versa" (Bloom-Wilson, as cited by Bowman, 2011, p. 52). The cornerstone idea at Arizona Western, however, may be its Global Leadership Retreat, which is when 80 students (half Americans and half international students) get to know each other off campus, over a long weekend, by participating in cross-cultural communication activities. The retreat has been so successful that international students leave the event more confident and optimistic about their sojourn in the U.S., and many go on to apply for leadership roles on campus (Bowman, 2011).

Additionally, several colleges and universities across the country are implementing a year-long transition program for international students. James Madison and George Mason Universities are two public research institutions of $\mathrm{HE}$ that have designed and implemented such initiatives. Their programs incorporate several classes in ESL coursework at the beginning of the degree program (Smith, 2011). The classes are restructured to provide a considerable amount of language support during students' first year in the country, when they struggle the most. A typical course schedule consists of general education core college requirements that inherently require hours of English language practice on a daily basis, such as composition and public speaking. Although transition programs are complex to design and set up, seem to work best for students who already have at least intermediate level English skills, and can add a year onto students' original degree requirements, the results of such programs may be well worth the challenges and investment. By and large, most of the international students in these programs exceeded the schools' expectations and went on to do as well or better than their American classmates in terms of GPA and adjustment to the academic system (Smith, 2011). These transition initiatives are interesting in that they are two-fold; the first part, for all practical purposes, is a mixture of acculturation strategies while the second encompasses their target academic program of study.

\section{Analysis of the Issue}

International students arrive in this country - a country that is markedly different in many ways for most of them - without family or friends to help them adjust to the culture and, as easy as it is to say 
that they will meet people and make friends, forming relationships takes time, effort, opportunity, and confidence, particularly when one moves to a foreign land (Shaules, 2007). The first six months to a year, especially, are extremely difficult for most international students and can be the turning point as to whether or not they ever acclimate to the culture (Bowman, 2011; Smith, 2011). Some international students, for instance, spend four years in the United States without making a single American friend (Yan \& David, 2011). While many meet and form friendships with other students from their own country or other countries, although helpful in forming relationships and overcoming loneliness, this does not usually facilitate assimilation into the American culture or result in contentment in their program experiences (Sawir, Marginson, Deumert, Nyland, \& Ramia, 2008). It is essential to combine students' academic and sociological experiences, as "the impact of college is most potent when in-class and out-of-class experiences are complimentary" (Kuh, as cited in Sandeen \& Barr, 2006, p. 145). Aside from going to class and working hard academically, international students also face the task of working on their social lives and forming out-of-class relationships with Americans.

However, the complexity of sociological, academic, cultural, and linguistic differences makes their integration into American culture a difficult one (Telbis, Helgeson, \& Kingsbury, 2014). Students from Asian countries, for example, are accustomed to a very different academic system where students listen, do not ask questions, and make limited eye contact with their instructors; hence, they must learn how to communicate and interact with their instructors in U.S. classes in ways they never have before (Telbis, Helgeson, \& Kingsbury, 2014). Some female students come from cultures where they have been very sheltered in general and have spent little time both by themselves and with males; they have to acclimate quickly to American social conventions and learn how to act in social situations in order to make friends (Problems for International Students, 2012). Furthermore, many students truly believe that the U.S. is like the television shows they have been watching for years and must accept and adapt to what seems like an entirely different place compared to what they were expecting once they arrive (International Students Culture, 2010; Yan \& David, 2011). Finally, the linguistic element is 
another problem that most international students face, as classroom language learning varies considerably from language learning in the target country (Scheffler, 2008). Even if a student has a high level of classroom-based English skill, for example, it does not normally translate into language proficiency when immersed in an environment of regional linguistic expressions, colloquialisms, cultural jargon, and accents. Speaking and understanding a foreign language in the target culture take an extended period of time (Rifkin, 2005).

\section{Implications for Leaders}

For many years, HE institutions have worked hard to enhance diversity on their campuses, which, in many cases, includes large international student populations. Cultural and systematic differences among countries, however, are affecting the quality and appeal of U.S. HE programs, a fact that administrators, faculty and staff must address in order to continue to attract international students to U.S. schools in a globally competitive HE market. Bloom-Wilson (as cited in Bowman, 2011) encouraged campuses to unify on this matter and include faculty, staff, and administrators on all levels to take part in programs that support international students' transition to America and the American HE system, but to cherry pick these individuals by "[identifying] who is sympathetic and understanding to the needs international students bring to a campus" (p. 53). The idea is that this collaboration between people who are genuinely, intrinsically moved to implement such programs will, over time, result in better quality initiatives and build a culture that supports the international student community. Likewise, doing so parallels research that cited authentic relationships as a base for acculturation (Jang, 2010).

Additionally, according to Rose-Redwood (2010) U.S. HE institutions are missing five major ways to help facilitate potential American/international interaction. The first one is individual department involvement by holding social functions that included both American and international students. The second is an incentivedriven conversation partner mentoring program that gives international students their first American friend and personal guide to their new culture. Incentives might include class credit hours or public service for resume building. Third, college and university clubs should sponsor some activities together to enhance the size and scope 
of the event and thus, publicity to draw more participants. Fourth, individual faculty, according to Rose-Redwood (2010), should make a special effort to pair American and international students for project and group work to foster dialogue and cross-cultural understanding. The fifth recommendation includes university-organized excursions to cities and states throughout the country as a way for students to interact and form friendships over a day-long trip, weekend or a week's time. Comparatively, these initiatives also align with Erikson's psychosocial theory that "the dominant developmental task for traditional college students, and other people of that same ages, is identity formation" (Sandeen \& Barr, 2006, p. 13), and should be a critical issue for student affairs. Most international students are not only learning how to acclimate to a new culture; they are also, simultaneously, maturing and forming their identities and individuality, just like their American classmates.

\section{Ideas for Sparking Interaction between International Students and Americans}

The following ideas, with the right planning and administration support, may help international students to improve their communication skills and spark authentic interaction between international students and Americans:

- A semester or two of intensive ESL courses and programs to prepare international students both culturally and academically, upon arrival, may give international students the base they need to make conversing and communication easier. An easier transition to the U.S. and higher academic accomplishments may be worth the possible additional time commitment and cost of such programs.

- A year-long service learning internship matching American students with international students may have merit for all participants. One (or two) Americans would be "assigned" an international student, and for one academic year, they would spend designated days and times per week with the international student for a total of at least 10 to 15 hours each week. Academically and professionally directed, the internship would require specific activities such as teaching international students about day-to-day life and cultural 
norms, and enjoying at least one social outing together each week.

- A fraternity/sorority type of group that celebrates intercultural friendships may be advantageous for outgoing personality types. International students and Americans would room together and share the responsibilities for the upkeep of the house as well as what meals to make and which social events to sponsor over the course of the semester.

- An International Hall that matches one American student with one international student per room may foster genuine interaction and friendship over time. Perhaps a personality questionnaire and a common interest survey could be utilized to best assign roommates. Additionally, universities could offer this unique international dorm option as a 1-credit internship (per semester) that includes a list of monthly expectations and activities to participating students, as well as a dorm chaperone to oversee and ensure a quality program.

\section{DISCUSSION AND CONCLUSION}

Clearly, spending extended, quality time with Americans helps international students with everything they need to acclimate to life in the U.S. American friends are their stepping stool into a new and different culture, and without them, their study abroad experience is greatly limited and altered culturally, socially, linguistically (Jang, 2010; Rose-Redwood, 2010), as well as academically, as "social integration and cultural adaptation directly and positively [correlate] to academic success" (Haydon, as cited in Korobova \& Starobin, 2015 , p.75). While the practical solution to this problem is to simply make friends and integrate into the American culture, it is not that simple. As implied by Gu, Schweisfurth, and Day (2009) and Sawir et al. (2008), forming relationships and fitting in are psychosocial processes that take time and effort on the part of multiple parties and that involve individual idiosyncrasies. It has to happen naturally in order to be authentic, and one way to facilitate this is for institutions of $\mathrm{HE}$ to communicate with the student body and hold seminars to bring awareness to the struggles of international students - but still, whether or not Americans and international students "hit it off," so to 
speak, is something that may or may not happen. In addition to making friends in class, the fastest and easiest way to learn about life in the U.S. and begin acculturation almost immediately is to live with American roommates or an American family (Jang, 2010; Yan \& David, 2011), but this is not always possible, as this option varies greatly by region, school, program, availability, and personal choice (writer's personal experience).

While definitely easier to address than the complexity of relationships, the aforementioned systematic issues that involve general sociological, academic, cultural, and linguistic differences also require the uniquely personal challenge of autonomy ( $\mathrm{Gu}$ et al., 2009; Sawir et al., 2008). International students must be able and willing to make the effort to learn about and adapt to their new environment. Likewise, American students must be made aware of the difficulty international students face and be willing to help them with their transition into the American culture. HE institutions can implement an array of programs to help international students with professor/student interaction, sociocultural conventions, and language learning strategies and opportunities, but the students themselves have to do their part, and it is not easy (writer's personal experience). As indicated by Sawir et al. (2008), "The university cannot solve every problem...through its own efforts. Often its role is to provide conditions that enable others to do so" (p. 174). Obviously, certain personalities are more adventurous, outgoing, more willing to try new things, and enthusiastically put themselves in situations that can be embarrassing or uncomfortable at times - for the sake of learning. Other personalities may be more introverted, timid, less willing to take social risks, anxious and resistant to change; people with these characteristics will almost surely struggle more and be less likely to fit in and adapt to what feels like a strange place (Sawir et al., 2008). Individual autonomy should never be overlooked or underestimated in the accomplishment of any goal; however, it is especially important when personality is a key factor in program results, which is the case with cross cultural relations (Shaules, 2007).

Additionally, it is important to recognize the sharp contrast between classroom language learning and immersion. International students study English in their native countries for many years before their journey to the United States; unfortunately, the inherent ceiling 
effect of classroom language learning impedes fluency. Approximately 10,000 hours of deliberate practice, or practice comprised of a long term commitment, autonomy in one's learning, and the willingness to work very hard, are required for an adult to become an expert in a language (Kolb \& Yeganeh, 2011). Although children accomplish this 10,000-hour task in their native language naturally by the time they are 5 years old, typical classroom-based learners receive only 600 hours of foreign language instruction (Ericsson \& Charness, 1994). Yet, international students are supposed to automatically adjust to a new culture, make friends, and understand the American way of doing things - expectations that are both unreasonable and tremendously stressful precisely because they are based on target language fluency.

Ultimately, it is crucial for colleges and universities across the nation to meet the needs of international students on their campuses and, while it may be true that "diversity generates more positive and robust learning communities... and is positively related to a variety of educational outcomes" (Schuh, Jones, Harper and Associates, 2011, p. 337), such diversity is accompanied by a myriad of challenges, not the least of which are individual idiosyncrasies of the many types of personalities required to make such an endeavor fruitful. The most profound insight of this analysis is that networking and building authentic friendships facilitate positive change, perhaps more than anything else, for international students. As one international student stated: "They [international students] just interact with the same people...So it's a question of how do you break down the barriers, how do you get people to interact?" (Sawir et al., 2008, p. 172). Indeed, these may be the toughest questions that HE student affairs offices have to answer: How do you break down barriers and how do you get people to interact? It is clear that quality interaction that has the potential to grow into relationships between Americans and international students is the bridge to successful acculturation, and that HE student services divisions have to build more and better bridges if they are to truly serve the needs of international students. 


\section{REFERENCES}

Bowman, K. (2011). Helping international students thrive on U.S. campuses. International Educator, 20(5), 50-53.

Bridges International. (2012). Student Facts. Retrieved from http://www.bridgesinternational.com

Ericsson, K., \& Charness, N. (1994). Expert performance: Its structure and acquisition. American Psychologist, 49, 709-724.

Gu, Q., Schweisfurth, M., \& Day, C. (2009). Learning and growing in a "foreign" context: International experiences of international students. Compare, 1-17.

Hurtado, S. (2007). Linking diversity with the educational and civic missions of higher education. The Review of Higher Education, 30(2), 185-196.

Institute for International Education. (2014). Open Doors Data. Retrieved from http://www.iie.org/Who-We-Are/News-andEvents/Press-Center/Press-Releases/2014/2014-11-17-OpenDoors-Data

International Students Culture. (2010). International Students.org. Retrieved from http://www.internationalstudents.org/culture.php

Jang, J. “A Study of International Students' adjustment Problems and Ameliorating Programs at Southwestern Baptist Theological Seminary." Ph.D. diss., Southwestern Baptist Theological Seminary, 2010.

Kolb, D., \& Yehaneh, B. (2011). Deliberate Experiential Learning: Mastering the Art of Learning from Experience. Retrieved from

http://learningfromexperience.com/media/2012/02/deliberateexperienctial-learning.pdf

Korobova, N., \& Starobin, S. S. (2015). A Comparative Study of Student Engagement, Satisfaction, and Academic Success among International and American Students. Journal Of International Students, 5(1), 72-85.

Orchowski, P. S. (2008). Foreign students come in record numbers. The Hispanic Outlook in Higher Education, 18, 44-44. 
Patron, M. (2014). Loss and loneliness among international students. Psychology Journal, 11(1), 24-26.

Problems for International Students. (2012). UCL Personal Tutor's Handbook. $\quad$ Retrieved from http://www.ucl.ac.uk/personaltutors/helpingstudents/commonp roblems/international

Rifkin, B. (2005). A ceiling effect in traditional classroom foreign language instruction. The Modern Language Journal, 89, 318.

Rose-Redwood, C. (2010). The challenge of fostering cross-cultural interactions: A case study of international graduate students' perceptions of diversity initiatives. College Student Journal, 44(2), 389-399.

Sandeen, A., \& Barr. M. (2006). Critical issues for student affairs: Challenges and opportunities. San Francisco, CA: JosseyBass.

Sawir, E., Marginson, S., Deumert, A., Nyland, C., \& Ramia, G. (2008). Loneliness and international students: An Australian study. Journal of Studies in International Education, 12(2), 148-180.

Scheffler, P. (2008). The natural approach to adult learning and teaching of L2 grammar. IRAL, 46, 289-313.

Schuh, J. H., Jones, S. R., \& Harper, S. R., \& Associates. (2011). Student services: A handbook

for the profession $\left(5^{\text {th }}\right.$ ed.). San Francisco, CA: Jossey-Bass.

Shaules, J. (2007). Deep culture: The hidden challenges of global living. Tonawanda, NY: Multilingual matters.

Simmons, J. (2011). Fostering a culture of inclusion: MIT takes a hard look at itself. The Hispanic Outlook in Higher Education, 21(13), 17-19.

Telbis, N. M., Helgeson, L., \& Kingsbury, C. (2014). International students' confidence and academic success. Journal of International Students, 4(4), 330-341. Retrieved from http://search.proquest.com/docview/1642598019?accountid=1 1107

Yan, K., \& David, C. B. (2011). An examination of individual level factors in stress and coping processes: Perspectives of Chinese 
international students in the United States. Journal of College Student Development, 52(5), 523-542.

DANIELLE GEARY, Ed.D., a Lecturer and Coordinator at the Georgia Institute of Technology, has been an international student herself, and roughly $20-30 \%$ of her students any given semester are international students. Some of her extensive international travel experience includes studying abroad, leading study abroad groups, living in Spain for several years, evaluating language institutes in Mexico, and conducting an ethnographical field study in Costa Rica. Email: dg808@gatech.edu

Manuscript submitted: June 6, 2015

Manuscript Revised: September 9, 2015 Accepted for publication: November 11, 2015 